\section{Variation Of Hepatic Enzymes With Vitamin B12 And D3 Levels In Cirrhotic Patients}

ORIGINAL

\section{Abstract}

Objective: To determine variation of hepatic enzymes Vitamin B12 and D3 levels in cirrhotic patients.

Design: Cross sectional study.

Setting: Cirrhotic patients in Abbasi Shaheed Hospital..

Participants: 250 patients in Abbasi Shaheed Hospital with diagnosis of cirrhosis including 141 males and 109 females.

Variable parameters: They include mean ALT, GGT, Alkaline phosphatase levels along with Vitamin B12 and D3 levels in blood.

Results: Vitamin B12 levels were $1249.59 \pm 487.01 \mathrm{pg} / \mathrm{ml}$ and $1422.28 \pm 627.75 \mathrm{pg} / \mathrm{ml}$ in males and females respectively while $\mathrm{Vi}$ tamin D3 levels were found to be $17.15 \pm 10.45 \mathrm{nmol} / \mathrm{L}$ in males and $14.80 \pm 14.24 \mathrm{nmol} / \mathrm{L}$ in females. Vitamin B12 levels were found to be positively correlated with the elevation of ALT and were negatively correlated with elevation of ALT, GGT and Alkaline Phosphatase. The ALT levels were $50.0 \pm 21.88$ in males and $14.80 \pm 14.24$ in females, Alkaline phosphatase to be $311.46 \pm 107.98$ in males while female Alkaline phosphatase were $346.47 \pm 101.60$. GGT levels to be $41.70 \pm 10.62$ in males and $45.01 \pm 13.74$ in females.

Conclusion: Cirrhotic patients suffering from severe hepatocellular damage have their elevated levels of Vitamin B12 and depressed Vitamin D3 levels in plasma accompanied by a positive association with elevated ALT and GGT plasma levels
Hasnain Abbas Dharamshi", Tufail Raza²,

Farwa Fatima ${ }^{3}$, Amber Batool ${ }^{4}$, Syeda Sara Fatima4, Syed Mohammad Ali Abidi ${ }^{5}$, Kiran Fatima ${ }^{4}$, Ahmed Aziz Siddiqui ${ }^{6}$, Mir Ali Raza Talpur ${ }^{6}$, Tahira Naqvi ${ }^{1}$, Ahmad Faraz ${ }^{1}$

\footnotetext{
1 Karachi Medical and Dental College.

2 Baqai Medical College.

3 Dow Medical College.

4 Sindh Medical College.

5 Jinnah University of Health Sciences.

6 Liaquat National Medical College.
}

\section{Contact information:}

Hasnain Abbas Dharamshi.

झdr.hasnain.dh@hotmail.com 


\section{Introduction}

Vitamin D maintains calcium homeostasis by interacting with the VDR in osteoblasts. It induces the expression of plasma membrane protein receptor activator of NF-kB ligand (RANKL). The RANK on the plasma membrane of pre-osteoclasts binds RANKL, which induces the pre-osteoclasts to convert into the mature osteoclast $[1,2,3]$. The mature osteoclasts are responsible for the release of hydrochloric acid and collagenases that dissolve bones and results into the releases of calcium and phosphorus into the blood circulation. Deficiency of Vitamin D is associated with the increased risk of colon, breast and prostate cancer [4], cardiovascular infections $[5,6]$ and autoimmune diseases. 25(OH), $D$ is used to measure the level of Vitamin $D$ in the circulation. It has a half-life of 2 weeks, and it correlates with secondary hyperparathyroidism, rickets, and osteomalacia [7]. Vitamin D deficient individuals develop abnormalities in glucose metabolism such as type 2 diabetes and hypertension, abdominal obesity, hyperlipidemia, and insulin intolerance. [8, 9] There is a strong association of vitamin D3 levels and the presence of liver disease. Vitamin D3 increases the expression of vitamin $D$ receptor (VDR) and inhibits the viral replication in cell culture [10]. It is also thought to increase the immunity by showing antimicrobial effects in both acute and chronic illness [11, 12]. In chronic liver disease, vitamin D is not converted into its active form, resulting in hypovitaminosis. Research showed that almost 2/3rd of the patients with chronic viral hepatitis had abnormal levels of vitamin D while 1/3rd had some deficiency.

Vitamin B12 is a water soluble vitamin necessary for normal neurological function and formation of Red Blood Cells. A deficiency can cause neuronal demyelination and axonal degeneration, and if left untreated will eventually result in neuronal death. Therefore, early diagnosis and timely treatment are imperative. [13]

Cirrhosis is defined as the histological development of regenerative nodules surrounded by fibrous bands in response to chronic liver injury, leading to portal hypertension and End Stage Liver Disease (ESLD). [14] Two of the main causes of hepatic fibrosis are viral hepatitis and alcohol abuse. [15] Globally, Hepatitis B virus is the major risk factor for the development of hepatocellular Carcinoma (HCC), Cirrhosis, and decompensated liver disease. [16] Also, Chronic HCV infection is accompanied by variable degrees of hepatic inflammation, damage to the liver and progressive fibrosis with an increased risk of progression towards Cirrhosis and HCC. [17] It is also seen that Alcohol accounts for $80 \%$ of all liver cirrhosis cases in district general hospitals in the UK. [18] Most of the cirrhotic patients die of liver-related causes, which may include acute bleeding and infections. [19] A study conducted at Alençon Hospital showed that $22 \%$ of deaths in Cirrhotic patients resulted from HCC, $12 \%$ from gastric bleeding and Liver Failure in $21 \%$ of cases. In $31 \%$ of patients, the cause was unrelated to cirrhosis, and in 13\% the cause was unknown. [20] Cirrhosis is the leading cause of death in Asia and it ranks as the tenth most common cause of death in US, [21] whereas worldwide, it is the $12^{\text {th }}$ most common cause. [22] According to W.H.O, the disease accounts for $1.8 \%$ of all deaths in Europe, causing around 170,000 deaths per year. [23] Medical treatments that may slow down the progression of compensated cirrhosis to decompensated cirrhosis are currently being developed. [24] Liver Transplantation, however, is the only option in a selected subgroup of patients with ESLD and HCC. [24]

\section{Materials and methods}

This is a cross sectional study conducted in Abbasi Shaheed Hospital from November 2013 to May 2014. The sample size of the study is 250. 141 patients were male while 109 were female patients. Those who were diagnosed of Cirrhosis and previously infected with Hepatitis B and C virus were 
included while patients taking vitamin supplements especially Vitamin B and Vitamin D complex were excluded. Diagnosis of the disease was based on clinical signs, laboratory abnormalities and ultrasound findings. The analytical parameters determined were Vitamin B12, D3, ALT and GGT levels in blood. SPSS 19 was used for statistical analysis.

Figure 1: Number of patients with hepatitis B \& $C$.

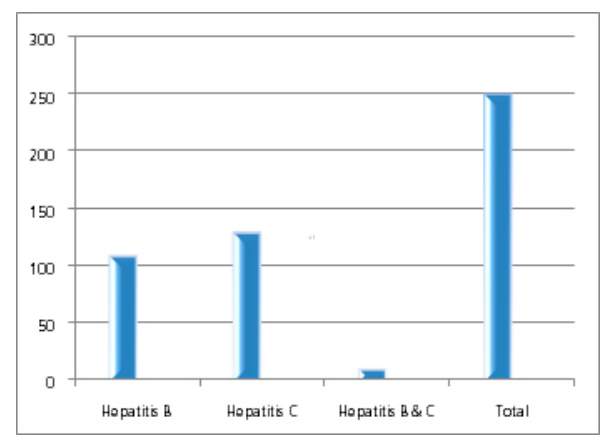

Figure 2: Number of male patients with hepatitis.

\section{Male Patients}

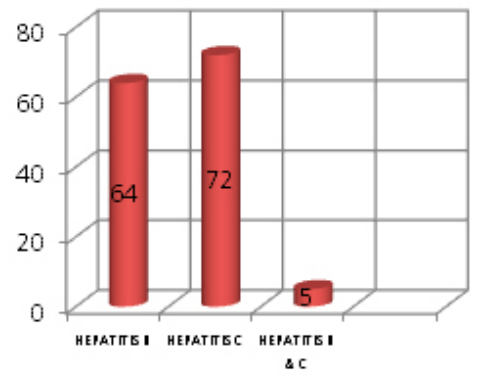

Figure 3: Number of female patients with hepatitis.

\section{Female Patients}

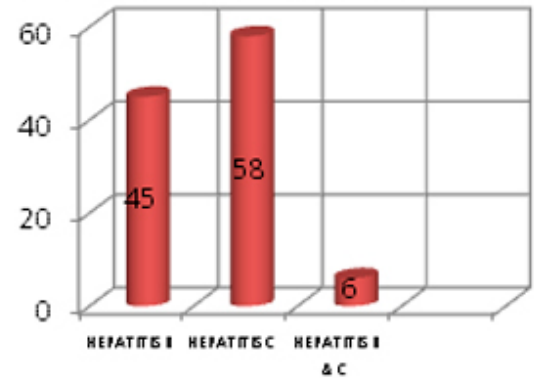

\section{Results}

The value of $R^{2}$ is 0.334 which means that the model explains 33.4\% variation of the dependent variable. The $P$ Value of $F$ statistic is $<0.001$ which means that the regression model is a good fit of the data.1 unit increase in ALT leads to 10.83 units increase in Vitamin B12 level, while 1 unit increase in GGT leads to 18.80 units increase in Vitamin B12 level, and 1 unit increase in Alkaline phosphatase leads to 15.02 units increase in Vitamin B12 level. The $p$ value of ALT, GGT and Alkaline Phosphatase is less than alpha which means that their coefficients are statistically significantly different from 0.

The value of $R^{2}$ is 0.37 which means that the model explains $37 \%$ variation of the dependent variable. The $P$ Value of $F$ statistic is $<0.001$ which means that the regression model is a good fit of the data.1 unit increase in GGT leads to 0.043 unit decrease in Vitamin D3 level while 1 unit increase in ALKALINE PHOSPHATASE leads to 0.043 unit decrease in Vitamin D3 level and 1 unit increase in ALT leads to 0.42 unit decrease in Vitamin D3 level.

The $p$ value of both Alkaline Phosphatase and ALT is less than alpha which means that their coefficients are statistically significantly different from 0 .

Table 1. Mean values of variables.

\begin{tabular}{|l|c|c|}
\hline & $\begin{array}{c}\text { Males (mean } \\
\text { value } \pm \text { s.d) }\end{array}$ & $\begin{array}{c}\text { Females (mean } \\
\text { value } \pm \text { s.d) }\end{array}$ \\
\hline Vitamin b12 & $1249.59 \pm 487.01$ & $1422.28 \pm 627.75$ \\
\hline Vitamin d3 & $17.15 \pm 10.45$ & $14.80 \pm 14.24$ \\
\hline Alt & $50.0 \pm 21.88$ & $50.96 \pm 11.20$ \\
\hline Gamma gt & $41.70 \pm 10.62$ & $45.01 \pm 13.74$ \\
\hline $\begin{array}{l}\text { Alkaline } \\
\text { phosphatase }\end{array}$ & $311.46 \pm 107.98$ & $346.47 \pm 101.60$ \\
\hline
\end{tabular}


Table 2. Regression analysis of vitamin b12 with other variables.

\begin{tabular}{|c|c|c|c|}
\hline Model & $\mathrm{R}$ & R Square & Adjusted R Square \\
\hline 1 & 0.578 & 0.334 & 0.313 \\
\hline \multicolumn{4}{|c|}{ ANOVA } \\
\hline Model & df & $\mathrm{F}$ & Sig. \\
\hline 1 & 3 & 16.02 & 0.0001 \\
\hline \multicolumn{4}{|c|}{ Coefficients } \\
\hline \multirow{2}{*}{ Model } & Unstandardized Coefficients & Standardized Coefficients & \multirow{2}{*}{ Sig. } \\
\hline & $\mathrm{b}$ & Beta & \\
\hline SGPT ALT & 10.83 & 0.236 & 0.007 \\
\hline Gamma GT & 18.802 & 0.48 & 0.0001 \\
\hline Alkaline Phosphatase & 15.02 & 0.43 & 0.003 \\
\hline
\end{tabular}

Table 3. Regression analysis of vitamin d3 with other variables.

\begin{tabular}{|l|c|c|c|}
\hline Model & $R$ & R Square try to explain more & Adjusted R Square try to explain more \\
\hline 1 & 0.60 & 0.37 & 0.35 \\
\hline
\end{tabular}

\begin{tabular}{|l|c|c|c|}
\hline \multicolumn{1}{|c|}{} & \multicolumn{3}{|c|}{ ANOVA } \\
\hline Model & Df & F & Sig. \\
\hline 1 & 3 & 28.58 & 0.0001 \\
\hline \multirow{2}{*}{ Model } & Unstandardized Coefficients & Coefficients & \\
\hline GGT & Standardized Coefficients & Sig. \\
\hline Alkaline & -0.043 & Beta & 0.471 \\
\hline Phosphatase & -0.043 & 0.053 & 0.0001 \\
\hline ALT & -0.42 & 0.334 & 0.0001 \\
\hline
\end{tabular}

\section{Discussion}

Around 170 million people worldwide have chronic hepatitis $\mathrm{C}(\mathrm{CHC})$ infection [25] causing a substantial burden of chronic liver disease globally [26]. The majority of subjects with $\mathrm{CHC}$ are vitamin D deficient $(<50 \mathrm{nmol} / \mathrm{L}) 27$ with $25 \%$ having severe deficiency $(<25 \mathrm{nmol} / \mathrm{L})$ [28]. In those with chronic liver disease the prevalence of vitamin $D$ insufficiency $(<75$ $\mathrm{nmol} / \mathrm{L})$ is almost universal, with vitamin $D$ deficiency $(<50 \mathrm{nmol} / \mathrm{L})$ present in around two-thirds of subjects [29]. Various studies suggest that vitamin D effects may play a significant role in the pathogene- sis of chronic liver diseases. [30] Even in the absence of cirrhosis, vitamin D deficiency is present in the majority of subjects. In those with cirrhosis, the prevalence of severe vitamin $D$ deficiency $(<25 \mathrm{nmol} / \mathrm{L})$ increases with increasing severity of synthetic liver dysfunction [31, 32]. Another study also showed that vitamin D supplementation improves response to antiviral treatment for recurrent hepatitis C. [33] Research showed that vitamin D supplementation during antiviral treatment of recurrent HCV patients result in frequent sustained viral response compared to those who were not supplemented.[34]. Harald 
[35] in his study demonstrates the inverse relationship between serum $25 \mathrm{OH}$ vitamin D level and HBV viral load rendering increased viral replication to be responsible for decreased $25 \mathrm{OH}$ vitamin D levels. [36] A study by Davide that included only patients with chronic hepatitis $C$, the occurrence of vitamin D deficiency $(\leq 20 \mathrm{ng} / \mathrm{mL}$ ) was observed in Alkaline Phosphataseproximately one-half of the patients and severe vitamin D deficiency $(\leq 10 \mathrm{ng} / \mathrm{mL})$ in Alkaline Phosphataseproximately $16 \%$ of them.[36] There were limitations to our study, including the cross-sectional design which does not possess any control group which limits the conclusions about directionality; viral load couldn't be performed due to the lack of funds.

Our findings suggest that cirrhotic patients admitted for complications presented with elevated plasma levels of vitamin B12 which were $1249.59 \pm 487.01 \mathrm{pg} /$ $\mathrm{ml}$ in males and $1422.28 \pm 627.75 \mathrm{pg} / \mathrm{ml}$ in females. The results also demonstrate a positive association between vitamin B12 and the hepatic enzymes where ALT is $50.0 \pm 21.88 \mathrm{pg} / \mathrm{ml}$ and $50.96 \pm 11.20$ $\mathrm{pg} / \mathrm{ml}$, and GGT is $41.70 \pm 10.62$ and $45.01 \pm 13.74$ $\mathrm{pg} / \mathrm{ml}$ in males and females respectively. It means that with increasing hepatocellular damage as indicated by elevated hepatic enzymes, serum vitamin B12 also tends to increase.[37] Very frequently it has been reported that cirrhosis leads to elevated vitamin B12 levels in serum. Our findings are in accordance with Hubertus et al, who studied male alcohol dependent patients with hepatocellular damage and found that the serum concentration of vitamin B12 was positively correlated with plasma ALT, AST and GGT. An explanation may lie in the fact that vitamin B12 bound with hepatocytes and storage of transcobalamin is disrupted in liver damage causing vitamin B12 to leak out of the liver into the circulation to produce severe tissue B12 deficits leading to metabolic dysfunction regardless of an elevated plasma total vitamin B12. [37]. Certain other studies also relate plasma vitamin B12 levels to the development of tumors or increased rate of deaths for this reason. Goel $A$ et al, in one of their study have also regarded vitamin B12 levels as a useful non invasive marker to differentiate non-cirrhotic portal hypertension from cryptogenic cirrhosis. [38] Johan F.B. Arendt et al, in their study have considered elevated vitamin B12 level as a proposal of diagnostic strategy. They unexpectedly got into consideration $8 \%$ of patients with high plasma vitamin B12 levels among patients with its deficiency. After summarizing the association between elevated levels and diseases, finally they concluded that after ruling out the risk of cancer, diseases of liver and kidney can be considered responsible for the elevation. [39] Areekul S et al; also found out that serum vitamin B12 levels in patients with infectious hepatitis and cirrhosis were higher than that of the normal subjects. [40] Furthermore, Lambert et al; in 1997, found a positive association of vitamin B12 with ALT only. [41] Our results demonstrate a substantial positive relationship with ALT as well as GGT.

\section{Conclusion}

Our results found elevated vitamin B12 levels in patients with liver cirrhosis and their positive affiliation with increased hepatic enzymes while decrease in Vitamin D3 levels associated with cirrhosis.

\section{Abbreviations}

ALT: Alanine transaminase.

GGT: Gamma-glutamyl transferase. 


\section{References}

1. Holick, M.F. 2004. Vitamin D: importance in the prevention of cancers, type 1 diabetes, heart disease, and osteoporosis. Am. J. Clin. Nutr. 79: 362-371.

2. Bouillon, R. 2001. Vitamin D: from photosynthesis, metabolism, and action to clinical Alkaline Phosphataseplications. InEndocrinology.L.J. DeGroot and J.L. Jameson, editors. W.B. Saunders. Philadelphia, Pennsylvania, USA. 1009-1028.

3. Khosla, S. 2001. The OPG/RANKL/RANK system. Endocrinology. 142: 5050-5055.

4. DeLuca HF. Overview of general physiologic features and functions of vitamin D. Am J ClinNutr. 2004; 80: 1689S-1696S.

5. McGreevy C, Williams D. New insights about vitamin D and cardiovascular disease: a narrative review. Ann Intern Med. 2011; 155: 820-826.

6. Artaza JN, Contreras S, Garcia LA, Mehrotra R, Gibbons G, Shohet R, Martins D, Norris KC. Vitamin D and cardiovascular disease: potential role in health disparities. J Health Care Poor Underserved. 2011; 22: 23-38.

7. Markestad, T., Halvorsen, S., Halvorsen, K.S., Aksnes, L., Aarskog, D. 1984. Plasma concentrations of vitamin D metabolites before and during treatment of vitamin D deficiency rickets in children. ActAlkaline Phosphataseaediatr. Scand. 73: 225-231.

8. Hypponen E, Boucher BJ, Berry DJ, Power C: 25-hydroxyvitamin $D$, insulin-like growth factor 1 and metabolic syndrome at age 45y: a cross-sectional study in the 1958 British birth cohort. Diabetes 2008, 57: 298-305

9. Moy and Bulgiba,2011: High prevalence of vitamin D insufficiency and its association with obesity and metabolic syndrome among malay adults in kuala lumpur,Malaysia,11: 735.

10. Gal-Tanamy M, Bachmetov L, Ravid A, Koren R, Erman A, Tur-Kaspa R, Zemel R. Vitamin D: an innate antiviral agent suppressing hepatitis $C$ virus in human hepatocytes. Hepatology. 2011; 54: 1570-1579

11. Holick MF: Vitamin D: evolutionary, physiological and health perspectives. Curr Drug Targets 2011, 12: 4-18.

12. Kamen DL and Tangpricha V: Vitamin D and molecular actions on the immune system: modulation of innate and autoimmunity. J Mol Med (Berl) 2010, 88: 441-50.

13. Liz da Silva, Carol Rees Parrish, Stacey McCray Vitamin B12: No One Should Be Without It. NUTRITION ISSUES IN GASTROENTEROLOGY, SERIES \#70, 2009.

14. Detlef Schuppan and Nezam H. Afdhal, Liver Cirrhosis. Lancet. 2008; 371(9615): 838-851.

15. Christian Mölleken, Barbara Sitek, et al, Detection of Novel Biomarkers of Liver Cirrhosis by Proteomic Analysis. HEPATOLOGY 2009; 49: 1257-1266.

16. Uchenna H. Iloeje Hwai-I. Yang Jun Su Chin-Lan Jen San-Lin You, Chien-Jen Chen, Predicting Cirrhosis Risk Based on the Level of Circulating Hepatitis B Viral Load, Gastroenterology Volume 130, Issue 3, Pages 678-686, March 2006.
17. UlrichSPENGLERand JacobNATTERMANN, Immunopathogenesis in hepatitis $C$ virus cirrhosis, Department of Internal Medicine 1, University of Bonn, Sigmund-Freud-Strasse 25, Bonn, Germany. Clinical Science (2007) 112, (141-155).

18. Kevin Walsh, Graeme Alexander, Alcoholic liver disease, 280 Postgrad Med J 2000; 76: 280-286.

19. Madhava Pai,1 Duncan Spalding,1 Feng Xi,1 and Nagy Habib1,2, Autologous Bone Marrow Stem Cells in the Treatment of Chronic Liver Disease, 1Department of HPB Surgery, Hammersmith Hospital, Imperial College, Hammersmith Campus, London, UK, 2Faculty of Medicine, Imperial College London, Hammersmith Campus, Du Cane Road, London W12 0NN, UK.

20. Mohammad A. Alsultan, Rashed S. Alrshed, and Abdulaziz S. Aldawood, In-Hospital Mortality Among a Cohort of Cirrhotic Patients Admitted to a Tertiary Hospital, Saudi J Gastroentero. 2011 Nov-Dec; 17(6): 387-390.

21. Anacréon S1, Bischoff F, Frenkiel J, Beaujard E, Cause of death in patients with cirrhosis, Rev Med Interne., 2001 Oct; 22(10): 926-33.

22. Kenneth D. Kochanek, M.A.; Jiaquan Xu, M.D. et al; Deaths: Preliminary Data for 2009, Volume 59, Number 4 March 16, 2011 National Vital Statistics Reports

23. Zatonski wA, sulkowska $U$, manczuk $m$, rehm j, boffetta $p$, lowenfels $A b$, et al. liver cirrhosis mortality in europe, with special attention to central and eastern europe. eur Addict res 2010; 16: 193-201.

24. Ignazio Grattagliano, Enzo Ubaldi, Leonilde Bonfrate, Piero Portincasa, Management of liver cirrhosis between primary care and specialists, World J Gastroenterol 2011 May 14; 17(18): 2273-2282

25. WorldHealth Organization. Fact sheet No164. http://www.who. int/mediacentre/factsheets/fs164/en/

26. Shepard, C.W., Finelli, L., and Alter, M.J. Global epidemiology of hepatitis C virus infection. Lancet Infect Dis. 2005; 5: 558-567

27. Petta, S., Cammà, C., Scazzone, C., Tripodo, C., Di Marco, V., Bono, A. et al. Low vitamin D serum level is related to severe fibrosis and low responsiveness to interferon-based therAlkaline Phosphatasey in genotype 1 chronic hepatitis C. Hepatology. 2010; 51: 1158-1167

28. Lange, C.M., Bojunga, J., Ramos-Lopez, E., von Wagner, M., Hassler, A., Vermehren, J. et al. Vitamin D deficiency and a CYP27B1-1260 promoter polymorphism are associated with chronic hepatitis $C$ and poor response to interferon-alfa based therAlkaline Phosphatasey. J Hepatol. 2011; 54: 887-893

29. Matthew T. Kitson, Stuart K. Roberts. D-livering the message: The importance of vitamin D status in chronic liver disease. Journal of Hepatology. 2011;57(4): 897-909.

30. Zuniga S, Firrincieli D, Housset C, Chignard N. Vitamin D and the vitamin $\mathrm{D}$ receptor in liver pathophysiology. Clin Res HepatolGastroenterol 2011; 35: 259-302.

31. Arteh, J., Narra, S., and Nair, S. Prevalence of vitamin D deficiency in chronic liver disease. Dig Dis Sci. 2010; 55: 2624-2628. 
32. Fisher, L. and Fisher, A. Vitamin D and parathyroid hormone in outpatients with noncholestatic chronic liver disease. ClinGastroenterolHepatol. 2007; 5: 513-520.

33. DavideBitetto; Vitamin D supplementation improves response to antiviral treatment for recurrent hepatitis C, Carlo Fabris, EzioFornasiere,CorradoPipan, Elisa Fumolo, Annarosa Cussigh1, Sara Bignulin, Sara Cmet, ElisabettaFontanini, EdmondoFalleti, RominaMartinella,MarioPirisiandPierluigiToniutto. j Transplant International 2011; 24; 43-50

34. HaraldFarnik: Low vitamin D serum concentration is associated with high levels of hepatitis B virus replication in chronically infected patients. JörgBojunga,Annemarie Berger, Regina Allwinn, Oliver Waidmann, Bernd Kronenberger1, Oliver T. Keppler2, Stefan Zeuzem1, Christoph Sarrazin1andChristian M. Lange. j. Hepatology 2013,58: 1270-1276.

35. CananDemir:Vitamin D levels in patients with chronic hepatitis $B$ virus infection and naturally immunized individuals Mehmet Demir, j Internal Medicine Inside 2013; 1; 52-54.

36. Complementary role of vitamin $D$ deficiency and the interleukin-28B rs12979860 C/T polymorphism in predicting antiviral response in chronic hepatitis C Davide Bitetto1 OFFICIALJOURNAL OF American Association for the Study of Liver Diseases VOLUME 53 ISSUE4 PAGES 1118-1126 ALKALINE PHOSPHATASERIL, 2011

37. Hubertus Himmerich et al; Vitamin B12 and hepatic enzyme serum level correlate in male alcohol- dependent patients, Alcohol \& Alcoholism Vol. 36, No. 1, pp. 26-28, 2001.

38. Goel A1, et al; Use of serum vitamin B12 level as a marker to differentiate idiopathic noncirrhotic intrahepatic portal hypertension from cryptogenic cirrhosis. Dig Dis Sci. 2013 Jan; 58(1): 179-87.

39. Arendt JF, Nexo E; Unexpected high plasma cobalamin : proposal for a diagnostic strategy, Department of Clinical Biochemistry, Aarhus University Hospital, Clin Chem Lab Med. 2013 Mar 1; 51(3): 489-96.

40. Areekul S, Panatampon P, Doungbarn J; Vitamin B12 and vitamin B12 binding proteins in liver diseases, Southeast Asian J Trop Med Public Health. 1977 Sep; 8(3): 322-8.

41. Lambert, D., Benhayoun, S., Adjalla, C., Gelot, M. M., Renkes, P., Gerard, P., Felden, F., Belleville, F., Gaucher, P., Gueant, J. L. and Nicolas, J. P. (1997) Alcoholic cirrhosis and cobalamin metabolism. Digestion 58, 64-71.

\section{Comment on this article:}
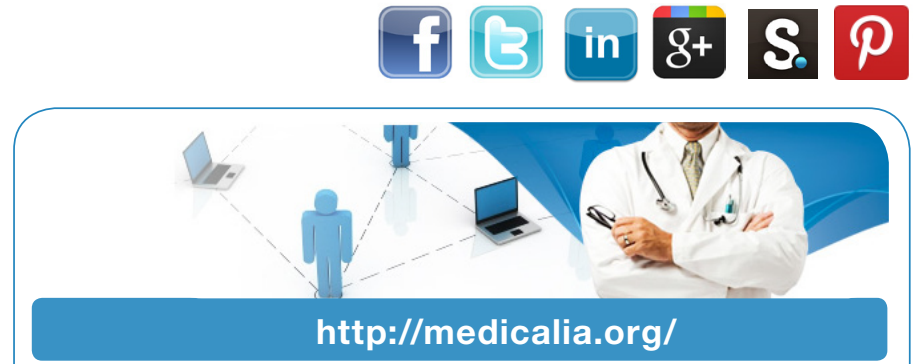

Where Doctors exchange clinical experiences, review their cases and share clinical knowledge. You can also access lots of medical publications for free. Join Now!

\section{Publish with iMedPub}

http://www.imed.pub

International Archives of Medicine is an open access journal publishing articles encompassing all aspects of medical science and clinical practice. IAM is considered a megajournal with independent sections on all areas of medicine. IAM is a really international journal with authors and board members from all around the world. The journal is widely indexed and classified Q1 in category Medicine. 